\section{Plastic Limit}

Jeffrey R. Keaton

Amec Foster Wheeler, Los Angeles, CA, USA

\section{Definition}

The plastic limit is one of the measured parameters of the Atterberg limits test (ASTM, 2010), which is used for differentiating consistency states of finer particles in soil material. If coarser particles are present (coarse sand, gravel, cobbles), the finer particles act as matrix and may govern the behavior of the soil mass. Consistency states depend on water content; with increasing water, the consistency states are solid, semisolid, plastic, and liquid.

The plastic limit is the water content at which a soil-water paste changes from a semisolid to a plastic consistency as it is rolled into a $3.175-\mathrm{mm}(1 / 8$-inch) diameter thread in a standard test. The second measured parameter of Atterberg limits test (ASTM, 2010) is the liquid limit. The Atterberg limits test also includes the plasticity index, which is calculated as the difference between the liquid limit and the plastic limit. All Atterberg limits are determined on samples of soil that pass the \#40 sieve (ASTM, 2009), which has $0.42-\mathrm{mm}$ openings (medium sand size and smaller, including silt and clay sizes, that may be part of the soil material).

\section{References}

ASTM (2009) Standard test methods for particle-size distribution (Gradation) of soils using sieve analysis. American Society for Testing and Materials Test D6913-04(2009)e1. http://www.astm.org/Stan dards/D6913.htm. Accessed April 2016

ASTM (2010) Standard test methods for liquid limit, plastic limit, and plasticity index of soils. American Society for Testing and Materials Test D4318-10e1. http://www.astm.org/Standards/D4318. htm. Accessed April 2016 